\title{
Study on Cellar Rainwater Treated by different size BAC in Villages and Towns of Northwestern China
}

\author{
Yaohui Yang \\ School of Environmental and Municipal Engineering, \\ Lanzhou Jiaotong University \\ Lanzhou, China \\ Yangyaohui198908@163.com \\ Guozhen Zhang \\ School of Environmental and Municipal Engineering, \\ Lanzhou Jiaotong University \\ Lanzhou, China \\ Guozhenzhang126@126.com
}

\author{
Hao Yang \\ School of Environmental and Municipal Engineering, \\ Lanzhou Jiaotong University \\ Lanzhou, China \\ haoyang@163.com \\ Rui Dang \\ School of Environmental and Municipal Engineering, \\ Lanzhou Jiaotong University \\ Lanzhou, China \\ ruidang@163.com
}

\begin{abstract}
In view of the micro-polluted cellar water quality characteristics of the northwestern town,we study natural biofilm with cellar water for coal activated carbon by $1 \mathrm{~mm}$, $2 \mathrm{~mm}, 3 \mathrm{~mm}$, and determine the biological activated carbon microbial adaptation period, biofilm growth, biofilm maturation time, and study the activated carbon of different size for the removal of pollutants. The results showed that : three little difference in the time period when three size activated carbon is biofilming.,but there is a difference of three particle size of activated carbon to remove pollutants for cellar water.
\end{abstract}

Keywords-cellar water treatment; different size; biological activated carbon; biofilm.

\section{INTRODUCTION}

Generally, the amount of microporous may reflect the activated carbon's degree of good or bad, micropores developed related to the particle size of the activated carbon[1].Studies have shown that the particle size of activated carbon influence the activated carbon adsorption capacity of the activated carbon, and the smaller the particle size, the better the adsorption[2]. In this paper, we will contrast the effect of coal activated carbon by different size $(1 \mathrm{~mm}, 2 \mathrm{~mm}$ and $3 \mathrm{~mm}$ ), and find a suitable activated carbon particle size for processing of cellar water treatment.

\section{TEST PART}

\section{A. Experimental raw water and activated carbon parameters}

Tab.1Quality of cellar rainwater

\begin{tabular}{|c|c|c|c|c|c|}
\hline $\begin{array}{l}\text { Imijeranire } \\
\text { (c) }\end{array}$ & PU & $\begin{array}{l}\text { Turbasy } \\
\text { (vru) }\end{array}$ & $\begin{array}{l}\text { [xulnat } \\
(m ;-1.1)\end{array}$ & $\begin{array}{l}\text { Ammanix } \\
\text { Hitrugen } \\
\text { \{ax L-1) }\end{array}$ & $\begin{array}{l}\text { tivest } \\
\text { (cm 's }\end{array}$ \\
\hline
\end{tabular}

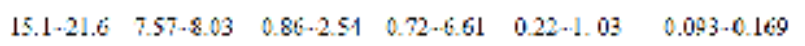

Tab.2 The performance parameters of activated carbon

\begin{tabular}{|c|c|c|c|c|c|c|c|c|c|}
\hline Material & Specification & Shape & $\begin{array}{c}\text { Iodine } \\
\text { value }(\mathrm{mg} / \mathrm{g})\end{array}$ & $\begin{array}{l}\text { Methylene } \\
\text { blue } \\
\text { value(mg/g) }\end{array}$ & $\begin{array}{l}\text { specific } \\
\text { surface } \\
\operatorname{area}\left(\mathrm{m}^{2} / \mathrm{g}\right)\end{array}$ & $\begin{array}{l}\text { Residue on } \\
\text { ignition( } \% \text { ) }\end{array}$ & $\begin{array}{l}\text { Fill } \\
\text { volume }\left(\mathrm{dm}^{3}\right)\end{array}$ & $\begin{array}{l}\text { Fill } \\
\text { weight }(g)\end{array}$ & $\begin{array}{l}\text { Place of } \\
\text { origin }\end{array}$ \\
\hline
\end{tabular}

$\begin{array}{lllllllll}\text { Coal } & 1 \sim 3 & \text { Granule } & >900 & 120-150 & >850 & <2 & 0.28 & 129\end{array}$

\section{B. The experimental device and process}

Test apparatus is shown in figure 1, Test device consists of high water tank and activated charcoal column composition, Three charcoal column diameter in order from left to right are $3 \mathrm{~mm}(1 \#), 2 \mathrm{~mm}(2 \#), 1 \mathrm{~mm}(3 \#)$.
Activated carbon column materials for organic glass, Inner diameter is $30 \mathrm{~mm}$, internal charcoal column from the bottom up are supporting layer and the filter layer. 
The supporting layer's hight is $100 \mathrm{~mm}$ which is equipped with pebbles of $10 \sim 20 \mathrm{~mm}$. Filter layer's hight which is equipped with is $400 \mathrm{~mm}$ thick activated carbon particles[3]. The distance from the top of the filter layer of activated carbon column end of the overflow population is about $250 \mathrm{~mm}$.

\section{Test methods}

Sampling at the same time each day during the test, Sampling location: The bottom of the activated carbon column, Laboratory indicators: Turbidity, Ammonia nitrogen, CODMn, UV254.

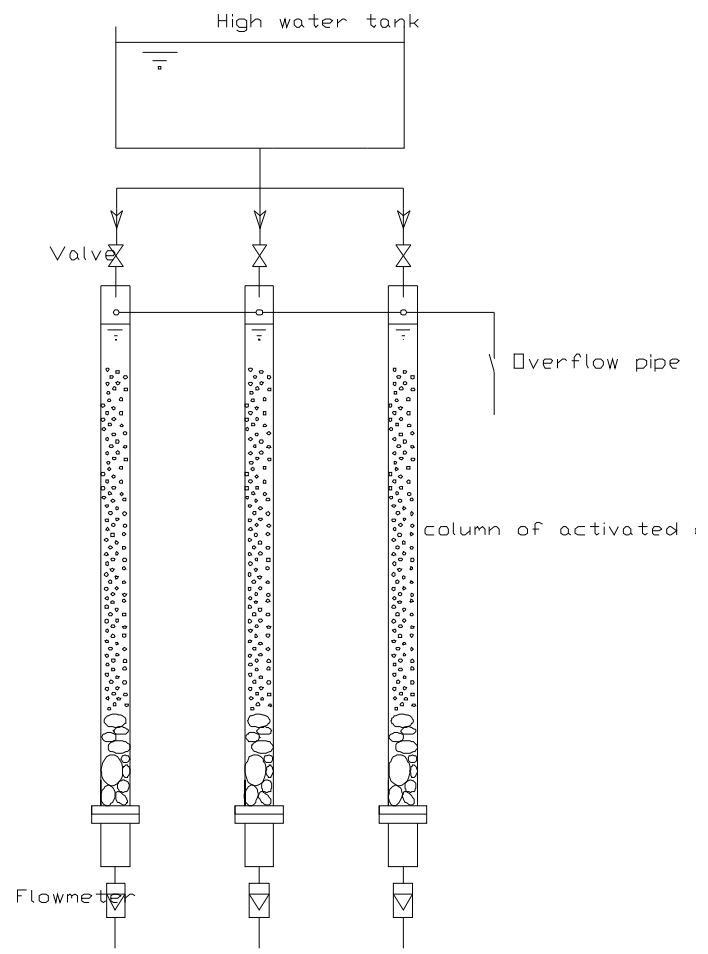

Figure.1 Test apparatus

\section{RESULTS AND DISCUSSION}

\section{A. Turbidity removal rate}

Fig. 2 shows that Four days before the activated carbon turbidity removal rate remains constant, 1,2,3 charcoal column average turbidity removal was $55.23 \%, 60.16 \%$, $68.83 \%$. The 4 th days of activated carbon for removal of turbidity began to decline. The reason is the beginning of the growth of microorganisms in the activated carbon column, Some secretions which discharge with running water let turbidity increase. The turbidity removal rate began to decline. The 9th day the turbidity removal rate is not in decline, and Began to steady developmentWhere the 3rd column of activated carbon's average removal rate is $36.12 \%$, The 2 nd column of activated carbon removal rate is $17.13 \%$, and the 3 rd column of activated carbon removal rate is $9.73 \%$, A few days' removal is negative. The reason for the lower turbidity removal efficiency is activated carbon activated carbon particle size distribution of a single. The bigger particle size, the higher the porosity between the activated carbon particle size, the more difficult to removal of turbidity.

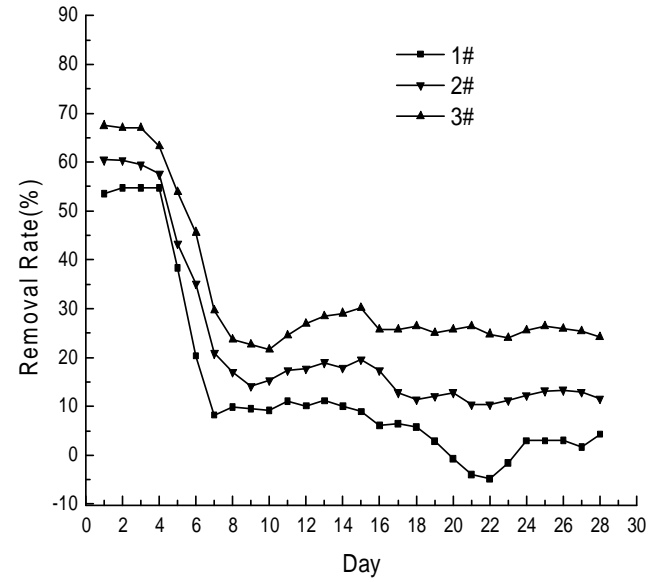

Figure.2 The turbidity removal rate 


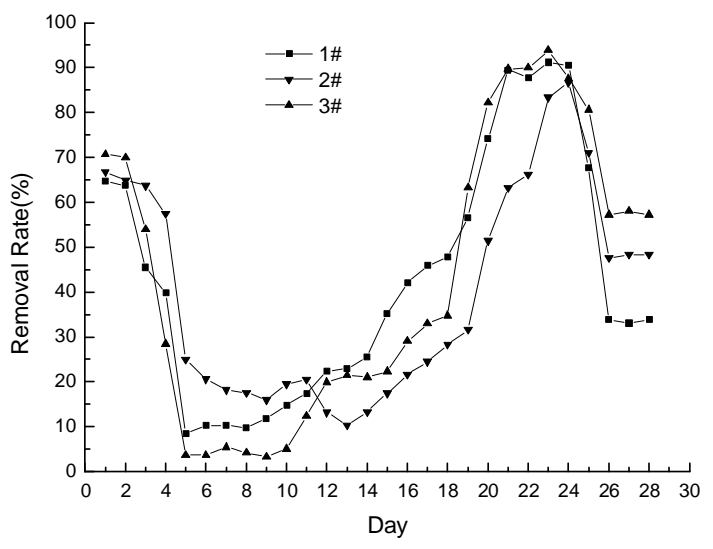

Figure.3 The NH3-N removal rate

\section{B. NH3-N removal rate}

Fig. 3 shows that the 3rd column of activated carbon's average removal rate of ammonia nitrogen is $70.12 \%$, the 2nd column of activated carbon is $65.23 \%$, the 1 st column of activated carbon is $64.11 \%$. The reason is that activated carbon remove ammonia nitrogen mainly by activated carbon adsorption for the first three days. The smallest particle size is the 3rd column of activated carbon,its adsorption properties is the best,so its removal rate is higher. the activated carbon adsorption capacity began to decline after 3 days. This period is not yet ripe for microbial growth,in this period it treat ammonia nitrogen in water by activated carbon adsorption. Activated carbon column for ammonia nitrogen removal rate began to increase at 10th day, This period isbiofilm growth time, ammonia nitrogen's removal rate is mainly by microbial. Fig. 3 shows that three charcoal column removal rate are basically the same.It reflect that the growth rate of nitrifying bacteria is substantially the same[4]. Activated carbon for the removal of ammonia nitrogen is stable at 26 th day. The 3rd column of activated carbon for removal of ammonia nitrogen is $45.13 \%$, the 1 st column of activated carbon for removal of ammonia nitrogen is $31.57 \%$. The reson is that activated carbon of 3 rd column has the biggest specific surface area.

\section{CODMn removal rate}

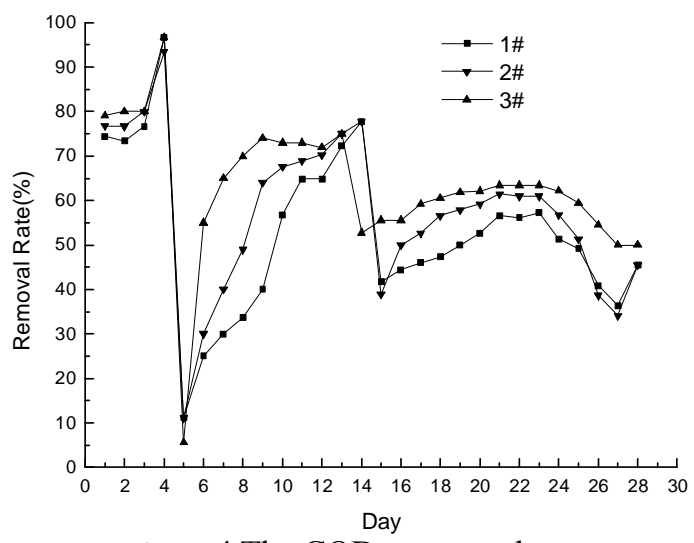

Figure.4 The $\mathrm{COD}_{\mathrm{Mn}}$ removal rate

Fig. 4 shows that the CODMn removal rate of the three activated carbon have little difference at the first four day. They are all at around $75 \%$. At this moment the CODMn is removed by activated carbon adsorption. In fifth day, the
CODMn removal rate of the activated carbon suddenly bottom out. The reason for it is the activated carbon adsorption reaching saturation. After the fifth day, microorganisms start growing,then the CODMn removal rate of the activated carbon begins to increase. The removal slope on the third column of activated carbon is maximum, which indicates that the microorganisms grow fastest followed by the second column of activated carbon. The first column of activated carbon is the minimum. Analysis of the reasons relates with the specific surface area. The larger the surface area, the more microbial attachment and the higher processing capacity[5]. After the fifteenth day, the CODMn removal rate of the activated carbon begins[6] to ease up, the removal curve becomes smooth. The average removal rate is $59.87 \%$ after the third column of activated carbon stability, followed by the second column of activated carbon is $49.63 \%$, the first column of activated carbon's average removal rate is $43.36 \%[7]$.

\section{UV254 removal rate}

Fig.5 shows that the UV254 removal rate of the activated carbon is relatively stable. The first five day,UV254 removal of activated carbon remains stable[8], the UV254 removal rate of the No.1, No.2 and No.3 column of activated carbon are $80.23 \%, 74.32 \%, 66.13 \%$. The UV254 removal rate decreases slightly at five to eight days. The eleventh day to the end of experiment UV254 removal rate remains smooth and stable[9], the UV254 removal rate are $73.32 \%, 60.23 \%, 50.65 \%$.

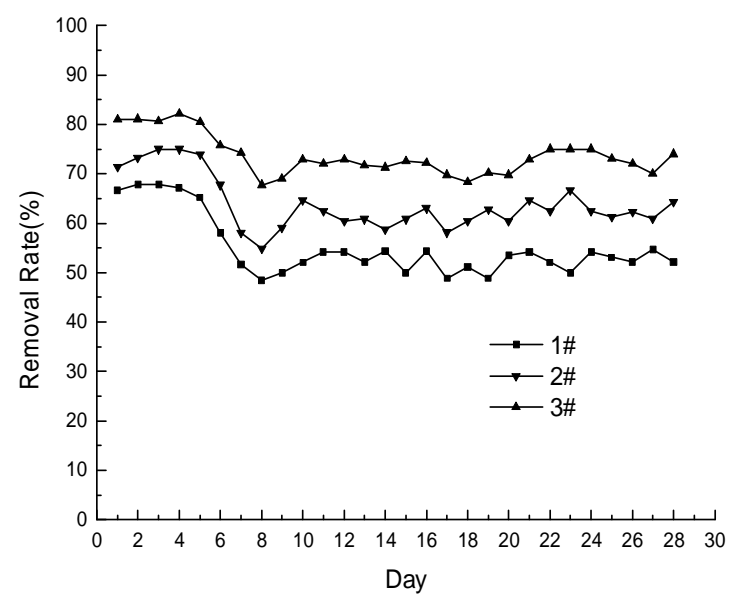

Figure.5 The $\mathrm{UV}_{254}$ removal rate

\section{CONCLUSIONS}

(1)The way of cellar water biofilm is natural biofilm. Particle size has no effect on activated carbon biofilm formation of three periods: microbial adaptation period(1$5 d)$, biological membrane growth period(5-15d), biological membrane maturation period(15-28d).

(2) The activated carbon particle size is smaller, the pore structure is more developed[10], the specific surface area is larger. The more easily microorganisms attach, the better treatment effect.

(3)The best treatment effect on the cellar water is the activated carbon particle size of $1 \mathrm{~mm}$. After the success of the biofilm and stable operation, the removal rate of turbidity, ammonia nitrogen, CODMn and UV254 are $36.12 \%, 55.23 \%, 59.87 \%$ and $73.32 \%$. 


\section{ACKNOWLEDGMENT}

This work was financially supported bythe China Schol arship Council

\section{REFERENCES}

[1] Zhong R C. Concise Water Design Manual [M]. China Building Industry Press, 1994.

[2] Li Z ,J, Shi B Y, Su Y, et al. 2013. L,ffect of particle size on adsorption kinetics of phenanthrene in water by powered activated carbon] ].Acta ScientiaeCircumstantiae,33 (1) :67-72.

[3] Liu Jianguang, Zhang Xiaojian, Wang Zhansheng. Influence of temperature on treating nitrification of high ammonia nitrogen source water in biological carbon filter[J]. China Environmental Science, 2004, 24(2) : 233 236.

[4] Wang Feng.Study on function and character of nitrifying bacteria in sewage treatment processes[D]. Shanghai:Tongji university, 2006.
[5] Cong Qiao, Cong Fuqi, Zhao Xiaoming, et, al. A new treatment for dining wastewater by using immobilized biologically activated carbon[J]. Journal of Safety and Environment, 2007, 7(2):49-52.

[6] Yang T, Lua AC. Characteristics of activated carbons prepared from pistachio-nut shells by physical activation[J].Journal of Colloid and Interface Science,2003,267(2):408-417

[7] Arenillas A, Rubiera F, Parra JB, et al. Surface modification of low cost carbons for their application in the environmental protection[J].Applied Surface Science,2005,252(3):619-624

[8] Ji YB, Li TH, Zhu L, et al. Preparation of activated carbons by microwave heating $\mathrm{KOH}$ activation[J].Applied Surface Science, 2007,254(2):506-512

[9] Girgis BS, Attia AA, Fathy NA. Modification in adsorption characteristics of activated carbon produced by $\mathrm{H}, \mathrm{P}$ under flowing gases[J].Colloids and Surfaces A-Physicochemical and Engineering Aspects,2007,299(1-3):79-87

[10] Attia AA, Girgis BS, Fathy NA. Removal of methylene blue by car bons derived from peach stones by H,POqactivation:batch and column studies[J].Dyes and Pigments,2008,76(1):282-289 